\title{
Renewable energy as a source of electricity for Murzuq health clinic during COVID-19
}

Wesam H. Beitelmal, Civil \& Environmental Engineering Departmest College of Engineering, Dhofar University, Salalah 211, Oman

Paul C. Okonkwo@, Fadhil Al Housni and Said Grami, Mechanical \& Mechatronics Engineering Department, College of Engineering, Dhofar University, Salalah 211, Oman

Wilfred Emori, School of Materials Science and Engineering, Sichuan University of Science and Engineering, Zigong 643000, Sichuan, People's Republic of China

Paul C. Uzoma, Department of Polymer and Textile Engineering, Federal University of Technology, Owerri, Nigeria

Paul C. Uzoma, ZJU-UIUC Institute, International Campus, Zhejiang University, Jianxing 314400, China

Barun Kumar Das, Department of Mechanical Engineering, Rajshahi University of Engineering \& Technology, Rajshahi, Bangladesh

Address all correspondence to Paul C. Okonkwo at pokonkwo@du.edu.om

(Received: 27 April 2021; accepted: 18 November 2021;

published online: 1 February 2022)

\section{ABSTRACT}

\section{Renewable energy offers a sustainable and environmentally friendly energy supply. The hybridization of the energy sources provides a better supply compared to individual sources and needs to be explored further.}

A great number of populations of the world, primarily in developing countries, are living in rural areas and are commonly isolated from the grid connection. Unstable power supply and increasing energy prices have significant effects on developing countries, especially during this COVID-19 pandemic. Renewable energy sources can provide sustainable and efficient electricity supply. Murzuq is a rural community situated in the southern part of Libya and endowed with renewable energy resources. While there is high electricity consumption during the lockdown, health clinics also experienced higher energy consumption of longer operating hours and an increased number of electrical appliances. This study investigates the techno-economic assessment of three different hybrid energy systems for health clinics in Murzuq. HOMER (Hybrid optimization model for electric renewables) software tool was used to evaluate the feasibility of employing renewable energy, to provide sustainable energy supply to the clinic. The current unsteady energy supply comes from the national grid and the current energy supply is not sufficient for the clinic's operating hours and requires a sustainable and steady supply. Measured data collected from the health clinic and HOMER software were used to analyze and optimize the change in overall electricity demand for the health clinic before and during the COVID-19 pandemic. The results showed that the photovoltaic/ battery hybrid energy system has a lower net present cost, compared to the Photovoltaic/Generator set/ battery hybrid energy system, but higher than the standalone generator set. However, the highest amount of carbon emission associated with the standalone generator set compared to the other two hybrid energy systems disqualifies it from being a suitable contender for the source of electricity for the health clinic. The photovoltaic/battery was deemed to be most economically beneficial in terms of emission reduction and energy price. The outcomes of this investigation will help stakeholders and designers to optimize hybrid energy systems that economically meet the health clinic energy demands, especially during this pandemic.

Keywords photovoltaic $\cdot$ cost $\cdot$ renewable energy $\cdot$ COVID-19 · fossil fuel

\section{Discussion}

- There has been an increase in energy demand during the COVID-19 pandemic.

- Among considered hybrid energy systems, renewable energybased systems provide sustainable and stable energy supply. 


\section{Introduction}

The spread of the COVID-19 has both immediate and protracted outcomes which have increased the cost of electricity, commodities, and has impacted economic activities in several ways. The pandemic has caused the death of thousands of individuals and has put millions of people unemployed. ${ }^{1}$ Moreover, the high contamination rate has put a stamped strain on both private and public organizations and incited governments to devote trillions of dollars to help support their people. ${ }^{2}$ The world's health systems are overpowered by this infection driving citizenry to practice self-isolation and social distancing resulting in a decline in industrial production due to sit-athome order and increased energy utilization. ${ }^{3}$ Because of this required quarantine, energy consumption, infrastructures, and accessories are sparingly being used, bringing about a radical increase in the oil price and energy cost around the world. ${ }^{4}$ Numerous production lines and organizations have been closed down, and livelihoods and communications have been crushed. ${ }^{5,6}$ The Covid-19 and its overall spread have had significant effects on the worldwide energy system.

Renewable energy which has thrived over years and appreciated quick development has been affected negatively because of the Covid-19 resulting in a low production rate. ${ }^{7}$ The COVID19 pandemic has struck the renewable energy manufacturing facilities, supply chains, and organizations and hindered the progress to renewables. ${ }^{7,8}$ Numerous nations' budgets have been adjusted, and the execution of new renewable energy projects is affected. ${ }^{9,10}$ For instance, the American-based Morgan Stanley organization diminished the establishment of the US solar photovoltaic (PVs) in 2020. ${ }^{8}$ Renewable energy utilization has found more applications because of considerable advancements, noteworthy approach structures, and innovation cost decline. ${ }^{11-14}$ Solar energy has gotten less expensive in recent years, and it was expected that renewable energy would dominate non-renewable energy sources. ${ }^{7}$ The economic results from the COVID-19 are extensive, with a positive impact on the advancement of renewable energy. Furthermore, a smart response can change these advert consequences over to some extraordinary opportunities. ${ }^{11,15}$ The new oil value decrease and the capriciousness of profits on fossil fuel could make the renewable energy business and opportunities stronger and grounded, specifically during the COVID-19 when the utilization of energy is significantly high. ${ }^{16,17}$

The renewable energy sources can be combined with either non-renewable or other renewable sources to form an efficient and sustainable hybrid energy system. ${ }^{18-22}$ The hybrid energy system can be either off-grid or grid-connected depending on the availability of the national grid and project objectives. ${ }^{19,23,24}$ In a hybrid energy system, components are connected to improve the system's reliability. ${ }^{20,25-27}$ Through hybrid energy system arrangement, steady and sufficient energy supply can be accomplished and emission from a single energy source can be diminished. ${ }^{28,29}$ The PV and wind energy sources are basic sustainable energy components incorporated in the hybridized energy systems and can also be organized as a standalone or hybrid energy system. ${ }^{28,30} \mathrm{~A}$ few examinations have been attempted to comprehend the hybrid energy systems regarding economic, environmental effects, and unwavering quality. ${ }^{19,31-33}$ Panapakidis et al. ${ }^{34}$ evaluated the technoeconomic achievability of four hybrid energy systems used to address the electrical energy needs of an off-grid home for 20 years in various geological areas in Greece. The examination revealed that the system with the lowest installation cost was set as a measure for providing the ideal electric solution for the communities. Nandi et al. ${ }^{35}$ inspected the choice of utilizing hybrid energy systems and standalone systems for rural electrification. A diverse financial analysis was considered in the study and the outcomes showed that a hybrid energy system has lower COE and NPC contrasted with a standalone diesel generator. Lorafe et al. ${ }^{36}$ played out a definite relative investigation of utilizing an off-grid hybrid energy system for an island community. Two hybrid energy systems were considered and the outcomes showed that hybrid energy is more practical and compelling than the standalone system.

The software has been used to simulate and understand the feasibility and techno-economic analysis and application of hybrid energy systems. ${ }^{37-39}$ The feasibility of using wind energy sources was studied using HOMER software. ${ }^{40}$ The result revealed that wind speed is an important factor when considering the application of wind energy. Several other authors have examined the feasibility of various renewable energy sources with HOMER software. ${ }^{41,42}$ HOMER software has widely been utilized for off-grid and grid-connected hybrid energy systems. ${ }^{43,44}$ It was reported that HOMER is generally utilized because of its sustainable energy-based system and can provide techno-economic and optimized results. These attributes make the HOMER software a likely instrument for evaluating hybrid energy systems.

In this study, measured data and HOMER were used to perform the feasibility study of using a renewable energy source to meet the electrical load demand of a health clinic in Murzuq. Murzuq in Libya is enriched with solar energy sources and assessment of the prevailing renewable energy sources has not been explored in detail. This is the first time renewable energy source is considered an alternative energy source for the health clinic. One of the advantages of the investigation is for the authority and policymakers to settle on supplanting the current standalone generator system currently used in the health clinic that adds to greenhouse emissions with the proposed renewable energy sources. This study also aims at providing a feasibility study and recommends the sustainable energy source for the clinic especially during the Covid-19 pandemic.

\section{Location of the study}

Murzuq located at $25^{\circ} 55.1^{\prime} \mathrm{N}, 13^{\circ} 55.6^{\prime} \mathrm{E}$ in southern Libya is considered in this study as shown in Fig. 1. Libya is currently encountering an energy crisis because of the power cuts that persevere for a very long time without demonstrated arrangements and solutions.

The power supply is deteriorating in Libya due to Libya's progressing common conflict, which has resulted in chronic power 
shortage, reduction in power generation capacity, and some communities not being connected to the grid. ${ }^{47}$ Murzuq was selected as the location of the study due to severe infrastructural damage to the grid network connection and the urgent need for electricity to treat pertinent especially during this COVID-19 pandemic. The strategic position and topographical scene of Murzuq make it viable and reasonable to harness environmentally friendly renewable energy. Renewable energy can help the community reduce reliance on fossil fuels. The selected location has potential for renewable energy by establishing a cleaner and sustainable environment with normal temperature in the 30 's. ${ }^{48}$ Running generator set (GS) for the entire clinic working hour requires a huge amount of fuel consumption and maintenance especially during this extended hour of operation due to COVID-19. As a result, many countries and facilities using GS as the source of electricity are shifting to investing in renewable energy which is economical and environmentally friendly.

\section{Methodology}

In HOMER software, hybrid configurations, capacities, climatic data, and load demand profiles are specified as shown in Fig. 2. Then the simulation is used to balance energy generation and consumption and calculate the costs. HOMER then displays a list of configurations, sorted by net present cost. In this process, the best solution is selected from among all scenarios depending on costs, reliability, and environmental benefits.

Through the methodology, the process of identifying the lowest hybrid energy cost system that satisfies the energy needs of Murzuq health clinic is presented. Measured load and weather data are utilized in the simulation and understanding of the hybrid energy systems and ensuring that the electrical needs of the health clinic are met.

\section{Description of the system components}

This part presents the synopsis of the technical details of the photovoltaic (PV) modules, inverter, the batteries (B), and the generator set (GS), which were utilized to perform the feasibility study and run the HOMER simulation. For an expected project

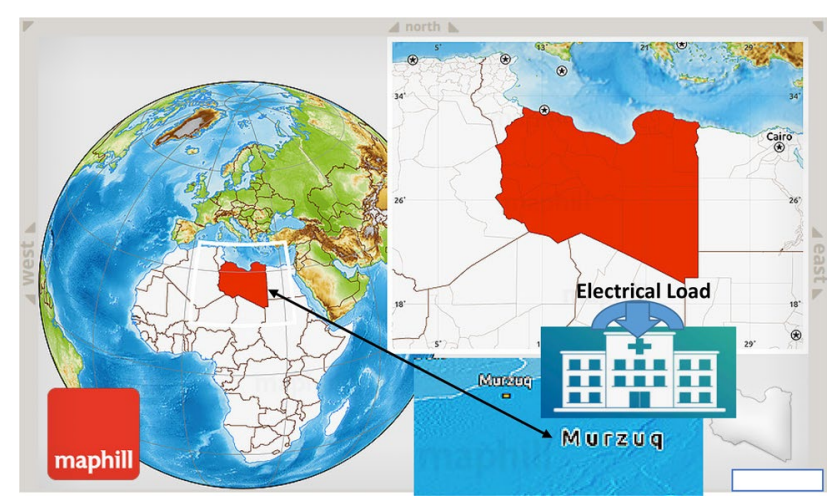

Figure 1. The geographical location of Murzuq in Libya. ${ }^{45,46}$ lifetime of 20 years, the annual interest rate was taken as $\mathbf{8 \%}$ and used in the optimization analysis. The measure of power generated by this hybrid arrangement relies upon the efficiency of the components. The load demand determines the capacity and sizes of the components. ${ }^{49}$ The metrological data used in the simulation were obtained from the NASA database based on the selected longitude and latitude of the clinic.

\section{Photovoltaic architecture}

For this study, a generic $1 \mathrm{KW}$ rated flat plate mono-crystalline PV is used and the cost of the PV panels is taken from the manufacturer's website. ${ }^{50}$ The cost of installation of the PV was not considered in the analysis. In this study, the size and orientation of the PV in terms of solar irradiation were considered as the PV is required to deliver electrical energy at the peak load. For optimal electrical energy generation, the position of the sun and the orientation of the PV surface are essential for solar system design. Based on the requirements, different orientations of the $\mathrm{PV}$ at different tilt angles were considered as shown in Fig. 3.

Figure 3 shows the PV system at different orientations $5^{\circ}$, $15^{\circ}$, and $25^{\circ}$. Each system is arranged mounted on a stand to enable the panel to be adjusted as shown in Fig. 3. The PV was designed to allow the solar panels to be adjusted toward the sun's rays to improve productivity and efficiency through maximum utilization of solar irradiation. It was reported that tilt angle has a significant effect on the solar PV system performance. ${ }^{51,52}$ Based on the size, number, and efficiency of the PV shown in Table 4 , the $15^{\circ}$ tilt angel has the average highest electrical energy production of $391.92 \mathrm{kWh}$ throughout the year with a peak of $445 \mathrm{kWh}$ in May as shown in Fig. 4.

The variation in electrical energy generation throughout the year is attributed to several parameters, but specifically on the daily hour of sunlight in the location of study. ${ }^{11,12}$

\section{Battery}

In a hybrid configuration, the battery that stores energy and can support the steady electric energy supply is often incorporated in the arrangement. ${ }^{53}$ In this study, a generic $100 \mathrm{KWh}$ Lithium iron phosphate battery of nominal capacity $100 \mathrm{KWh}$, and nominal bus voltage of $600 \mathrm{~V}$ was used. The economic and technical characteristics of the selected generic $100 \mathrm{KWh}$ Lithium iron phosphate battery are obtained from HOMER energy software. ${ }^{49}$ The battery bank attains its stored capacity when a maximum state of charge $(100 \%)$ is reached through the surplus energy produced by renewable and non-renewable energy.

\section{Diesel generator architecture}

Generators are accessible in a wide range and the applications significantly depend on the electrical load demand. ${ }^{54}$ A 100Kva HL-Perkins-GS was used to supply a steady power supply to the required health clinic load and charge the battery system. The cost of the GS was $\$ 580 / \mathrm{KW}$ and the current diesel price in Libya is $\$ 0.52 /$ liter and often fluctuates due to government policies. ${ }^{55}$ Power generation from the GS largely depends on the capital cost, operation, and maintenance costs such as fuel cost, 


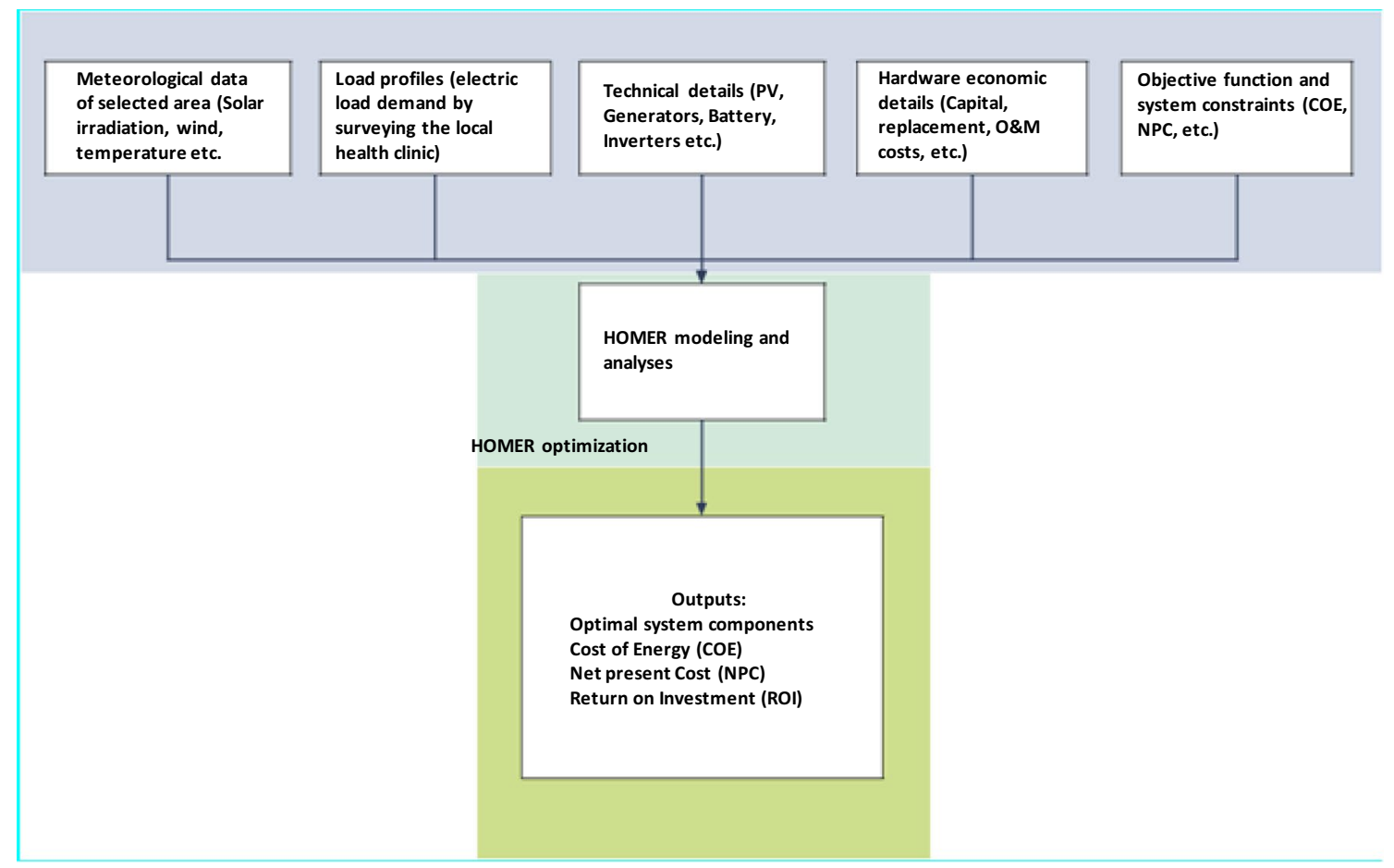

Figure 2. Overview and methodology of the feasibility study.

a

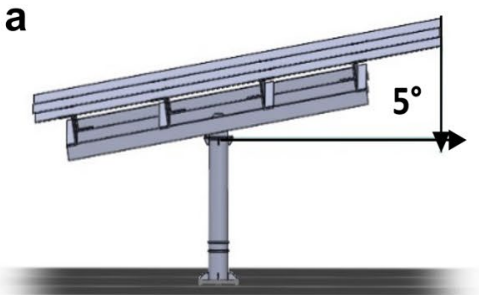

b

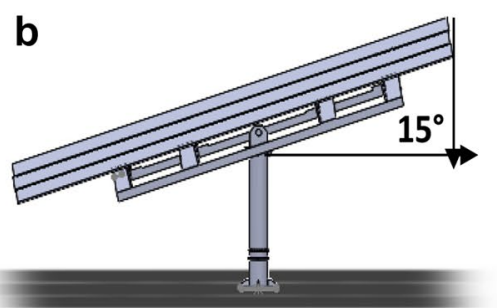

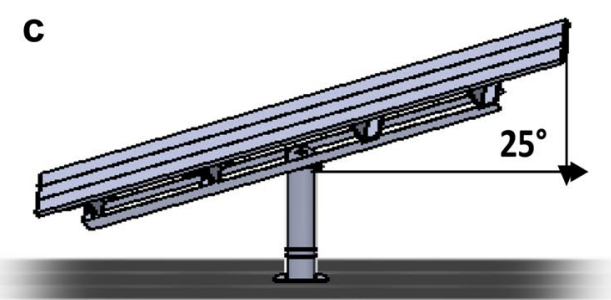

Figure 3. Schematic diagram of PV tilt angles considered.

the replacement cost of GS, and the lifetime of GS. The present study does not consider the sensitivity of the diesel fuel cost.

\section{Inverter}

When considering the utilization of inverter in the hybrid energy system, factors such as efficiency, operation, and maintenance costs of the component have to be ascertained. A generic bi-directional inverter system that converts direct current (DC), generated from the PV to Alternating current $(\mathrm{AC})$ and vice versa was used in the study. The lifetime of the inverter used in the hybrid energy component was alleged to be 15 years with an efficiency of $92 \%{ }^{56}$ The technical parameters of the components used for the investigation are shown in Tables 1, 2, and 3.

\section{Homer software and system validation}

HOMER software was used in our recently published study which demonstrates the validity of the model used in this present

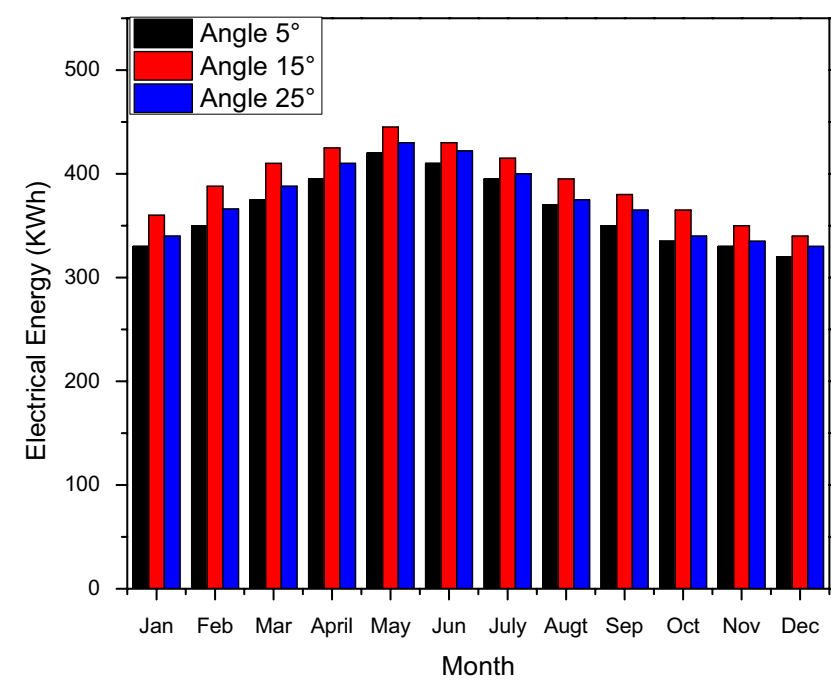

Figure 4. Murzuq's location monthly PV production at different tilt angles. 
study. ${ }^{57}$ In the software, input parameters are added and the outputs analyzed as part of the feasibility study. Moreover, HOMER's outputs and results are widely accepted in recent relevant researches. ${ }^{41,42}$

\section{HOMER analysis and hybrid energy system arrangement}

A hybrid energy arrangement contains at least two or more energy sources joined to deliver a productive and efficient source of power than the individual energy sources. By joining distinctive electric energy sources, the impediments of every one of the energy sources can be limited. ${ }^{45,46}$ The outline of the proposed hybrid energy system is displayed in Fig. 5.

Figure 5 shows the proposed hybrid arrangement as executed in the Homer simulation software. The hybrid systems considered are (a) PV/GS/B, (b) GS, and (c) PV/B. The monthly average data of global radiation in the Murzuq were used as input in the HOMER simulation. The system comprises the PV panel, generator, and boards, storage batteries, and inverter. The PV panel produces direct current (DC) power and is connected to the DC bus of the system. The inverter changes over the DC generated to Alternating Current (AC). Following the arrangement, the system supplies electric power to the load. However, if the generated electrical power exceeds the load required in the health clinic, the excess energy is used to charge the storage batteries that supply power to the health clinic when the load demand exceeds power generation. In the plan, a converter is utilized to change over the DC power output from renewable energy to AC power that is utilized by the health clinic load. Joining the battery into the hybrid energy system guarantees that the surplus electricity delivered by the PV or the GS sources is stored in the battery. ${ }^{47}$ The specifications of these hybrid energy systems represent the system cost, arrangement, productivity, and efficiency. The current hybrid energy system arrangement components and properties are shown in Table 4.

The selection of each hybrid arrangement depends on its contribution and economic viability. ${ }^{29,31,54}$ HOMER executes the size optimization of the system components with an aim of finding a hybrid energy system that provides the minimum net present cost (NPG) or cost of energy (COE).$^{58}$ In this study, a HOMER technology developed by Natural Renewable Energy Laboratory (NREL) was used in the simulation and technofinancial evaluation. Given the financial appraisal, the best hybrid energy system is selected.

\section{Health clinic load profile}

To provide the required power for the health clinic, an assessment of the load demand is necessary. The health clinic's load profile was measured as a result of a detailed survey performed at the health clinic as shown in Table 5.
Table 1. Mono-crystalline silicon PV solar.

Table 2. Diesel generator specification.

\begin{tabular}{l} 
Parameter \\
\multicolumn{2}{c}{ Value Units } \\
\begin{tabular}{|l|c|c|}
\hline Maximum power & 500 & Wp \\
\hline Optimum operating voltage & 36,5 & $\mathrm{~V}$ \\
\hline Module efficiency & 15.6 & $\%$ \\
\hline Operational life & 20 & $\mathrm{yr}$ \\
\hline
\end{tabular}
\end{tabular}

Parameter
\begin{tabular}{|l|c|c|}
\hline Hours of operation & 4857 & $\begin{array}{c}\text { hrs/ } \\
\text { yr }\end{array}$ \\
\hline Efficiency & 15 & $\%$ \\
\hline Operational life & 25 & yr \\
\hline Capacity factor & 80 & $\%$ \\
\hline
\end{tabular}


Table 3. System inverter specification.

Parameter
\begin{tabular}{|l|c|l|}
\hline Mean output & 12 & $\mathrm{~kW}$ \\
\hline Minimum output & 0 & $\mathrm{~kW}$ \\
\hline Maximum output & 18 & $\mathrm{~kW}$ \\
\hline Capacity factor & 90 & $\%$ \\
\hline
\end{tabular}

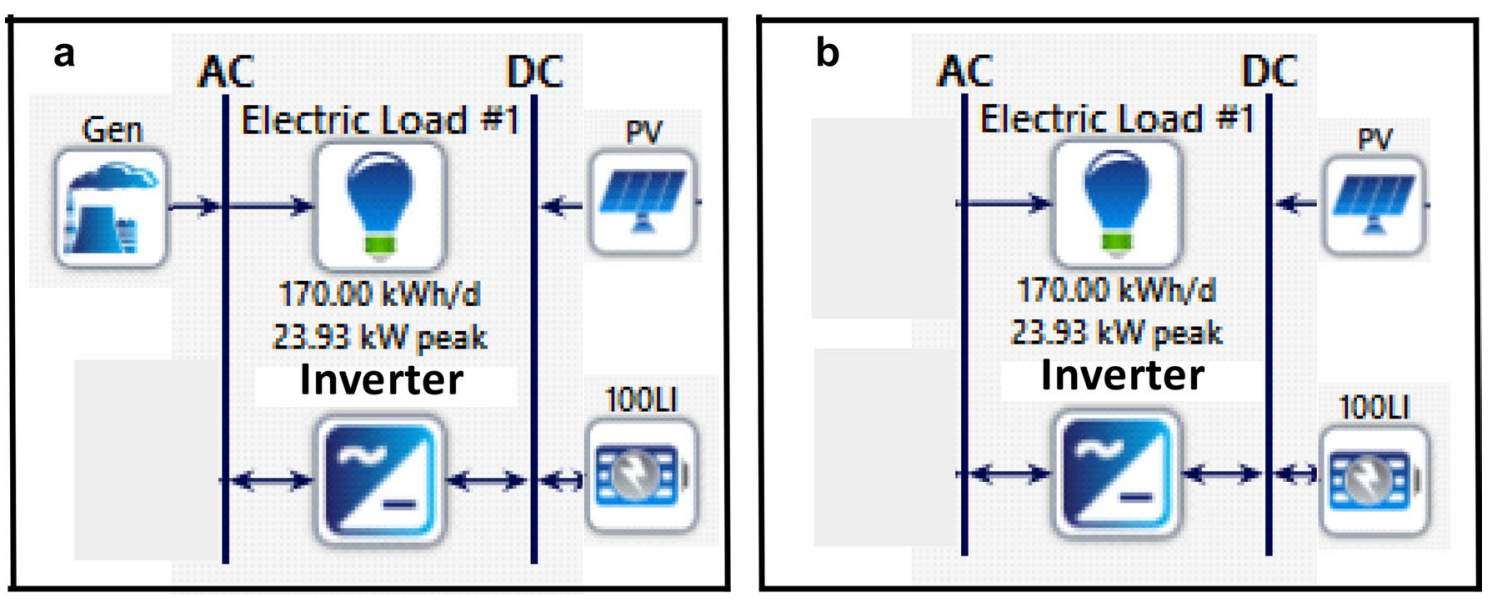

C

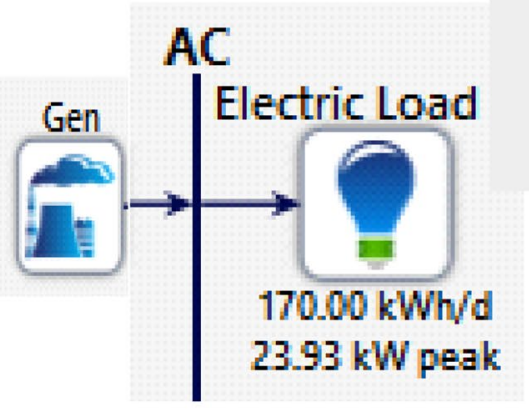

Figure 5. The considered hybrid arrangement.

However, the health clinic's loads can vary with time and duration based on the clinic's busy operation. The health clinic is located in the Murzuq community and also provides health services and treatment to the surrounding communities. It is important to report that the health clinic doctors and nurses provide treatment to patients on a non-residential basis, hence reducing the number of apartments in the health clinic. The health clinic has five rooms including receptions and toilets lighted with lamps for external lighting which would operate for $12 \mathrm{~h}$ from 18:00 to 6:00 h. The health clinic operates from 8:00 to 22:00 h each working day. However, during the Covid-19, the health clinic increased its operation hour from 8:00 to 24:00 h due to an increased number of patients resulting in increased electrical load as evident in Fig. 6 .

It can be seen in Fig. 6 that the electrical load increased significantly during the Covid-19 as compared to load utilization before the Covid-19 and can be attributed to the increase in the equipment and extended hour of the equipment operation due to increased number of patients in the health clinic during the pandemic. Krarti et al. ${ }^{59}$ revealed that while there is a decrease in the 
Table 4. System component.

No \begin{tabular}{l} 
Component \\
\hline 1
\end{tabular}
\begin{tabular}{|l|c|c|c|c|}
\hline Generator & Autosize Genset & 12.5 & 1 \\
\hline 2 & PV & Generic flat plate PV & 1 & 15 at $1.6 \mathrm{~m}^{2}$ size each \\
\hline 3 & Storage & $\begin{array}{c}\text { Generic } 100 \text { KW Lithium } \\
\text { iron phosphate }\end{array}$ & 10 & 10 \\
\hline 4 & System inverter & Inverter & $20 \mathrm{KVA}$ & 15 \\
\hline
\end{tabular}

energy consumption in the industrial sectors due to lock-down measures, the residential and operational facilities have seen a significant surge of up to $30 \%$ in energy utilization. It requires that the surge in energy consumption be complemented with the shift to alternative renewable energy sources especially for rural communities where GS has to work for a longer hour period due to the COVID-19 pandemic.

The day-by-day load profiles were dictated by computing the power demand (Kwh/day) for all load types in the health clinic during the year. HOMER software utilizes two methods of either, day-to-day or step-to-time-step randomness in calculating the load profile. ${ }^{49}$ In HOMER software, an algorithm controls the operating hours of the load's usages using a probabilistic approach $^{41,60,61}$.Figure 7 shows the typical daily load profiles during the normal working day and HOMER software utilizes hourly load for its simulation.

It is shown that between 16:00 and 24:00 have the most noteworthy energy utilization peak load of $10 \mathrm{KW}$ contrasted with the other hours of the day. During this time of the day, residents have closed from work, and generally, people that need medical attention visit the clinic for medical examination. It is estimated that the electrical load demand increased during the COVID-19 pandemic as shown earlier in Fig. 6.

\section{Solar radiation information}

To get the ideal performance of the PV system, it is critical to gather and evaluate the meteorological information, specifically solar radiation and temperature of the site. Figure 8 shows the month-to-month normal estimations of global solar radiation over the Murzuq in Libya.

The sun radiates its energy and most of the energy is transferred radially as electromagnetic radiation. The photovoltaic cells convert solar radiation into renewable energy. It is obvious from Fig. 8, that solar energy intensity on the locale is extremely high particularly between April and June with average daily radiation during May being $7.42 \mathrm{KWh} / \mathrm{m}^{2} /$ day and the yearly normal global solar radiation $5.43 \mathrm{KWh} / \mathrm{m}^{2} /$ day. The clearness index is displayed as a fraction resulting from solar radiation. The software utilizes the data from the latitude and longitude position of the plane to obtain the clearness index. Figure 8 shows the corresponding variation in the clearness index and is associated with the weather of the current study location.

\section{Measured peak temperature}

Figure 9 shows the monthly peak temperature information of Murqan health clinic, Libya. The measured peak temperature profile of the health clinic facility utilizing a computerized thermometer appears in Fig. 9

The peak measured temperature is the maximum temperature that occurred in each day. A peak temperature of $30.72{ }^{\circ} \mathrm{C}$ is recorded during May in the year 2020. HOMER programming utilizes the normal temperature of an area in deciding the PV power proficiency. ${ }^{49}$ It is realized that the user productivity of sustainable power sources firmly relies upon the dominating ecological conditions. ${ }^{41,44}$ Thus, a reasonable relationship can be seen between the solar radiation displayed in Fig. 8 and the day-by-day temperature shown in Fig. 9.

\section{Economic feasibility analysis criteria}

The feasibility study and economic consideration between various proposed hybrid arrangements are performed dependent on the NPC and COE. ${ }^{62,63}$ Homer is utilized to compute the NPC that addresses the current expense cost and the salvage. The present cost incorporates the capital cost, replacement cost, and operating and maintenance of the entire system over the project life cycle. The NPC can be assessed utilizing Eq. (1). ${ }^{64}$

$$
\mathrm{NPC}=\frac{C_{\mathrm{ann}, \mathrm{tot}}}{\operatorname{CRF}(i, N)}
$$

where; $C_{a n n}$, is the annualized total cost of the whole system (\$/year).

CRF represents the capital recovery factor.

$N$ is the project life cycle. 


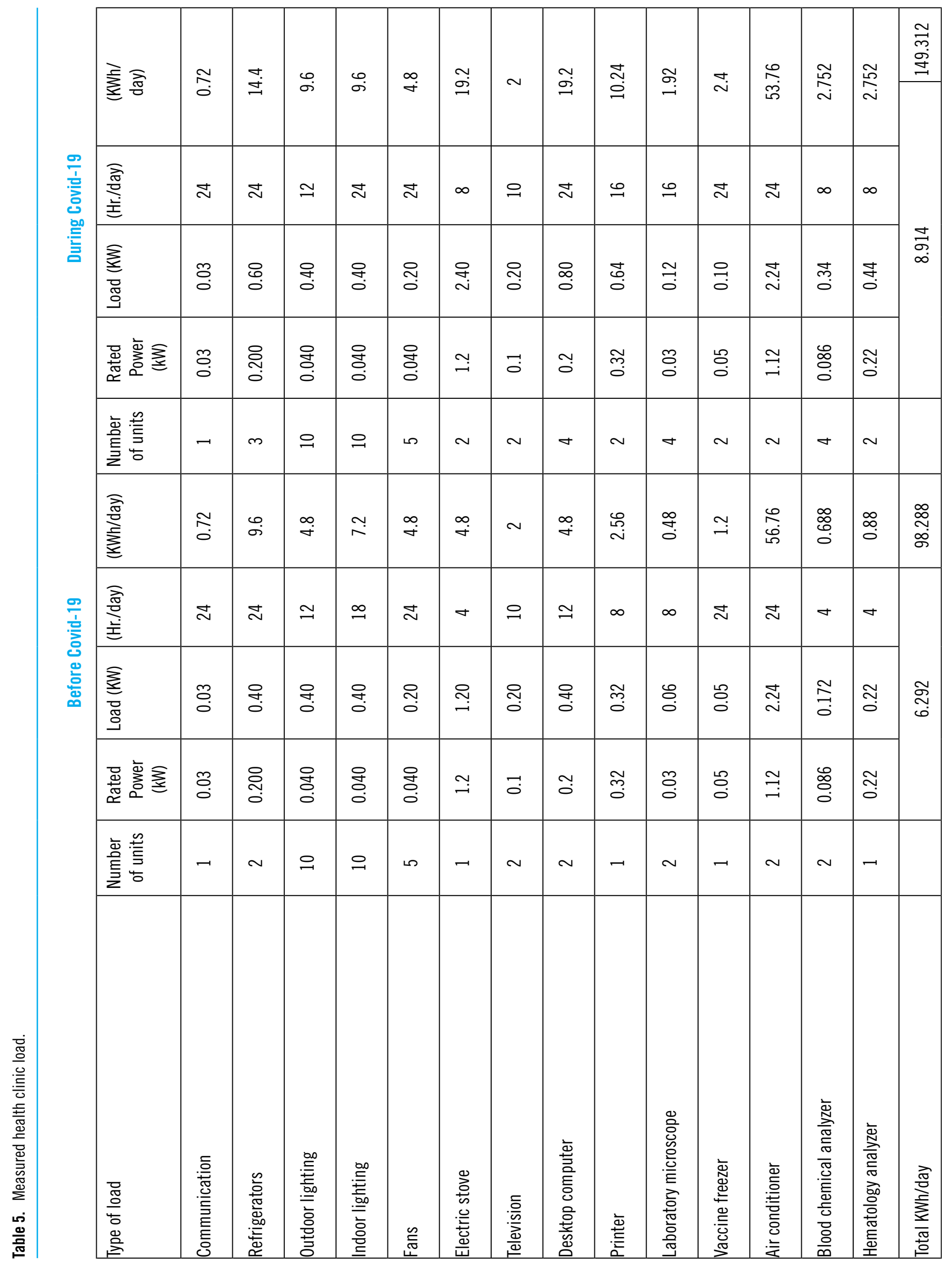




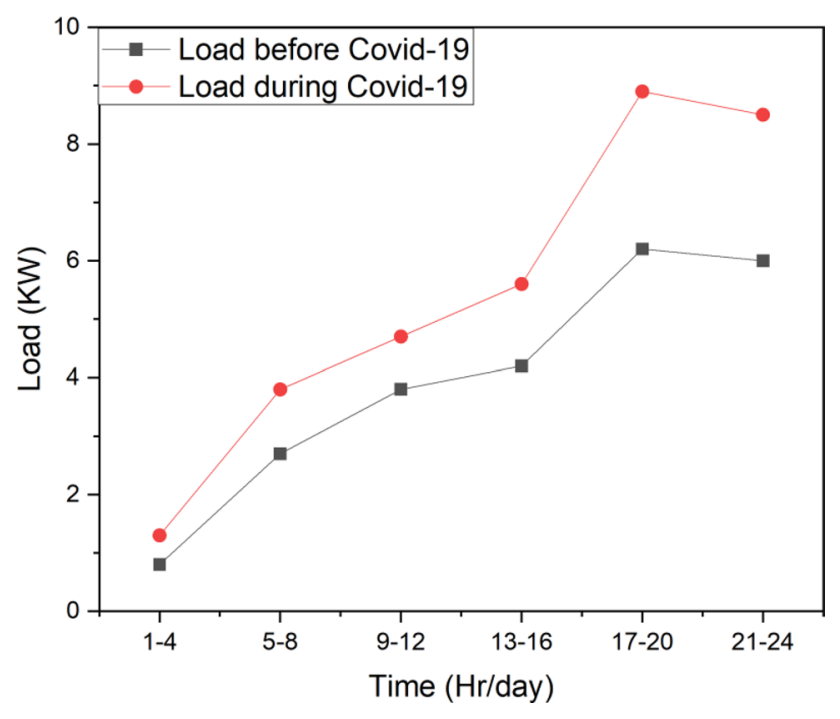

Figure 6. The measured daily load profile.

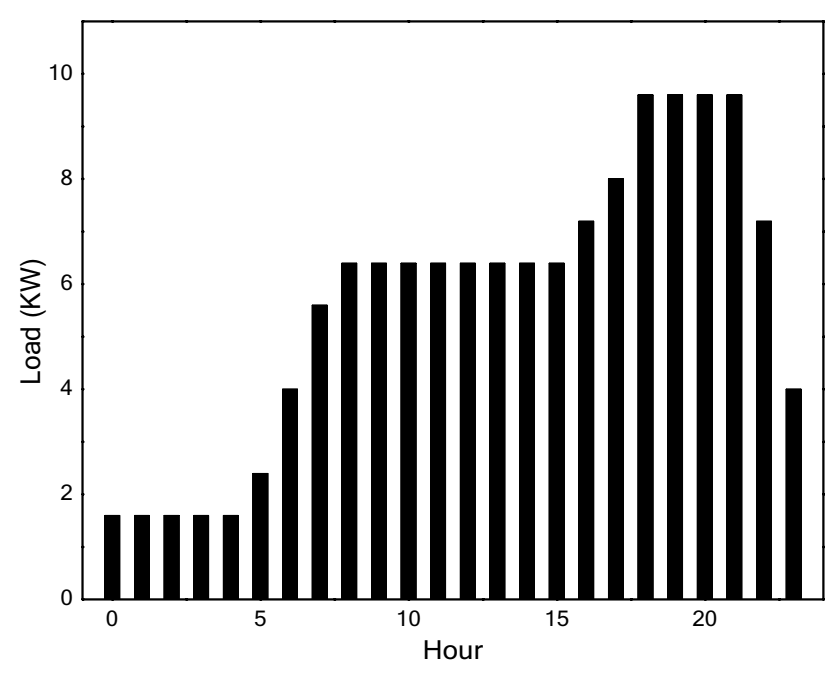

Figure 7. Daily load profile of the Health Clinic.

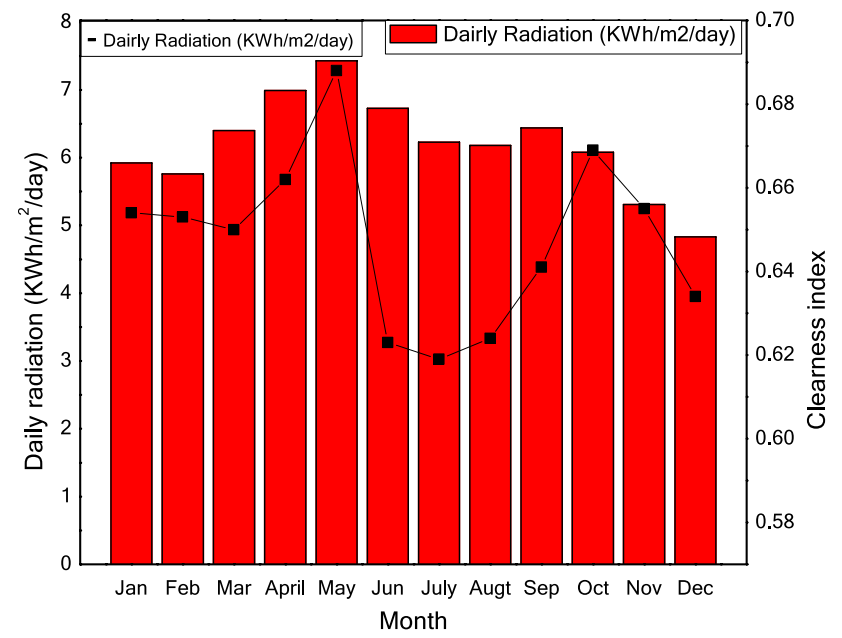

Figure 8. Solar radiation. $i$ is the yearly real interest rate and it can be calculated using Eq. (2) [34].

$$
i=\frac{i^{0}-f}{1-f}
$$

where;

$i^{0}$ represents the nominal interest rate.

$f$ is the annual inflation rate.

The cost of energy (COE) is defined as the average cost of energy unit (KWh) and can be calculated using HOMER by dividing the total annual cost of the entire system by total energy produced throughout the same year. The COE can be calculated using Eq. 3. ${ }^{65}$

$$
\mathrm{COE}=\frac{\mathrm{TAC}}{E_{\text {anloadserved }}}
$$

where: $E_{\text {anloadserved }}=$ the total yearly load served by the system in KWh.

To strengthen the feasibility analysis of systems, return on investment (ROI) is considered. In the economic analysis, the feasibility study is also calculated by utilizing the ROI. HOMER determines the return on investment using the following Eq. $4 .{ }^{49}$

$$
\mathrm{ROI}=\frac{\sum_{i=0}^{R_{\text {proj }}} C_{i, \text { ref }}-C_{i}}{R_{\text {proj }}\left(C_{\text {cap }}-C_{\text {cap }, \text { ref }}\right)}
$$

where;

$C_{i, \text { ref }}$ means the Reference system nominal annual cash flow, $C_{i}$ stands for the Current System nominal annual cash flow, $R_{\text {proj }}$ represents project lifetime in years, $C_{\text {cap }}$ represents capital cost of the current system, $C_{\text {cap,ref }}$ stands capital cost of the base system.

The economic data in relation to capital, operational, and replacement costs of different hardware components and their lifetime are shown in Table 6.

\section{Economic assessment result}

In this examination, the HOMER software determines the annualized capital cost by equally spreading the capital and fixed operating costs of the hybrid energy system components over a venture's anticipated lifetime of the systems. ${ }^{41,62}$ Homer blends and matches the system components to find what assortment fulfills the health clinic load requirement at the lowest NPC and COE. Figure 10 shows the operating cost and NPC of the hybrid energy systems. The NPC, operating cost, and COE are the fundamental economic criterion utilized to examine the feasibility of a given hybrid energy system. ${ }^{67}$ It was accounted for that the NPC and COE are viewed as a proper indicator to assess the ideal arrangement for renewable hybrid energy systems when contrasted with the non-renewable hybrid energy system. ${ }^{68,69}$

It can be seen from Fig. 10 that of all the three hybrid energy systems compared, the PV/B has the lower NPC and operating cost of $\$ 30,500$ and $\$ 4120$, respectively, compared 


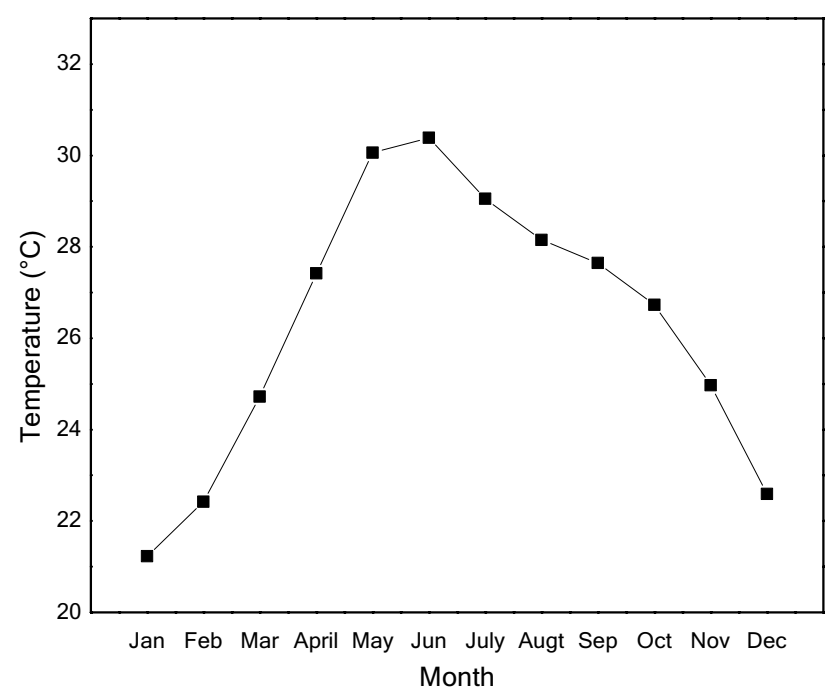

Figure 9. The measured peak temperature profile of Murzuq Clinic in Libya.

to the PV/GS/B that has NPC and operating cost of $\$ 42,330$ and $\$ 8772$, respectively. The standalone generator set has the lowest NPC and operating costs of $\$ 580$ and $\$ 316$, respectively. The low NPC and operating cost observed in the renewable energy-based hybrid energy system can be credited to the immediate connection between solar radiation and the NPC and operating cost. ${ }^{69}$ Among the three hybrid energy systems considered in this study, the PV/GS/B, PV/B, and GS have COE values of $0.1550,0.1500$, and 0.1655 , respectively. Wesam et al. ${ }^{57}$ reported that the higher the solar radiation, the more energy is generated through the renewable energy sources, the lower the NPC and COE. When the temperature and solar radiation are high in a given location, the energy generation appears predominantly high due to the association between solar radiation and the energy generated from the PV. ${ }^{70}$ Due to increased energy generation as a result of high solar radiation, more energy is produced, and operating cost, NPC, and COE are low as evident in the PV/B hybrid energy system shown in Fig. 10.

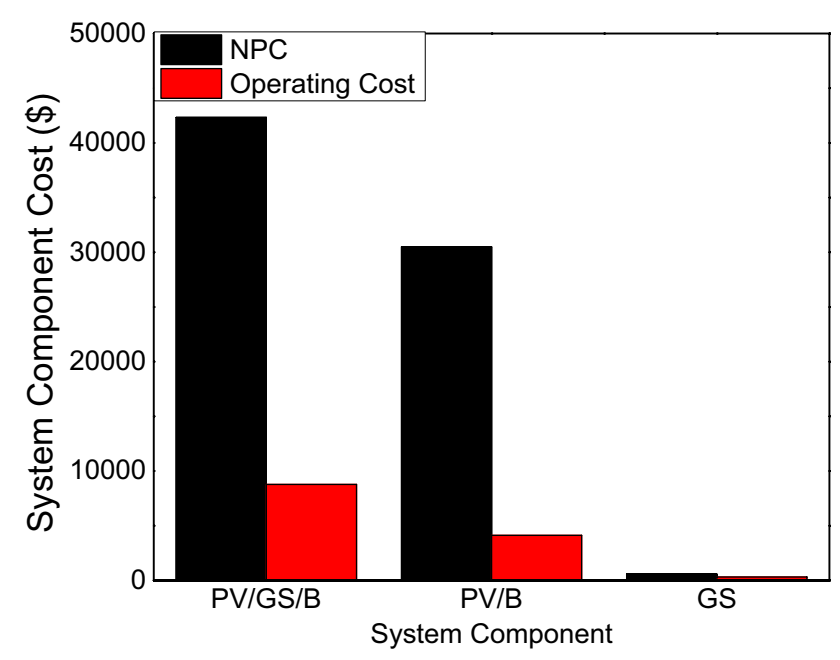

Figure 10. Operating cost and NPC of the hybrid energy systems.

\section{Electricity generation result}

Figure 11 shows the normal month-to-month electrical production, consumption, and excess of the various hybrid energy systems. Figure 11 shows that for the PV/B and GS hybrid energy systems, $100 \%$ of the electric production is provided by PV component and GS, respectively. The correlation of electric production for the three hybrid energy systems shows that the PV/B, PV/GS/B, and GS hybrid energy stems generated a total of 106,298 KWh/yr., 109,788 KWh/yr., and 74,823 KWh/yr., respectively. Although the energy generated by the three hybrid energy systems can adequately supply the demanded electrical load before and during the COVID-19 pandemic, the electricity generated by the PV/B and PV/GS/B hybrid energy systems are relatively double the required load as shown in Fig. 11. In terms of economic analysis, the lowest NPC, COE, and operating cost recorded for the PV/B hybrid energy system in contrast to the other two hybrid energy systems present the PV/B to be the most viable candidate for the health clinic energy source.

Figure 11 shows that the PV/GS/B, PV/B, and DG hybrid energy systems have electrical utilization of $36,892,32,942$,

Table 6. Technical and economic data for different hardware components. ${ }^{66}$

Replace-

ment cost

Items

Capital cost (\$)

(\$)

0 \& M cost (\$) Lifetime (yr)

\begin{tabular}{|l|c|c|c|c|}
\hline PV module & $1300 / \mathrm{KWp}$ & - & $12 / \mathrm{yr}$ & 20 \\
\hline Lithium iron phosphate battery & 1100 & 1000 & $10 / \mathrm{yr}$ & 10 \\
\hline Inverter & 750 & 700 & 7 & 15 \\
\hline Diesel generator & $580 / \mathrm{kW}$ & $420 / \mathrm{kW}$ & $0.05 / \mathrm{hr}$ & 25 \\
\hline
\end{tabular}




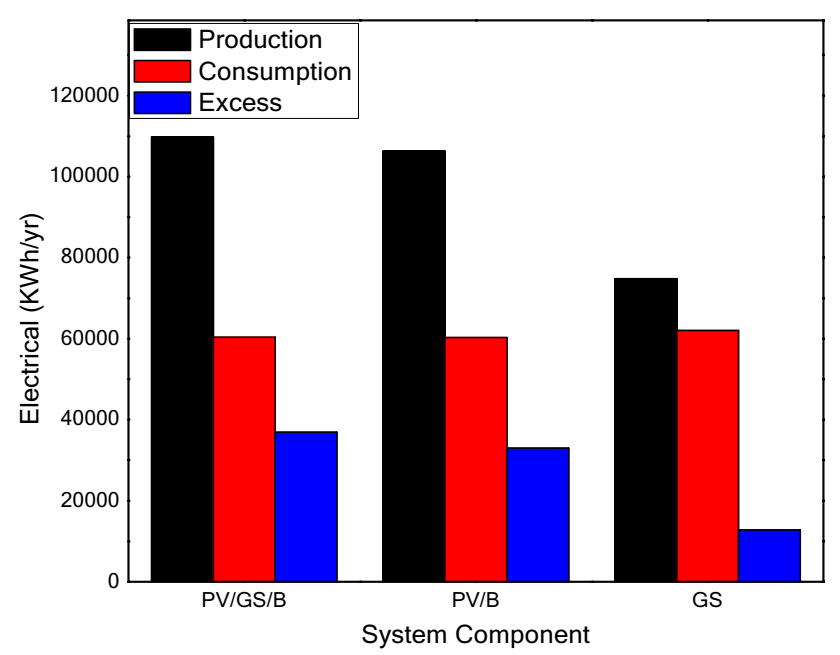

Figure 11. System electrical energy.

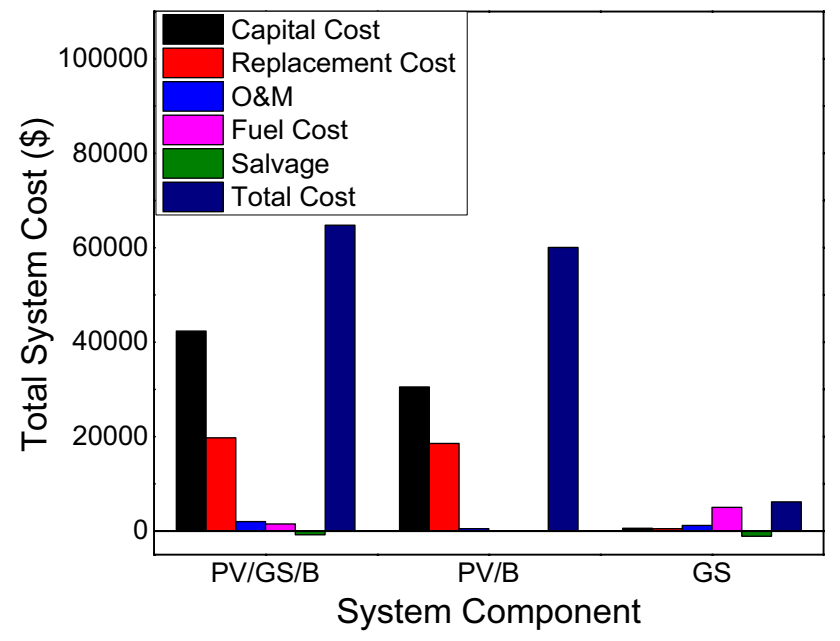

Figure 12. System cost analysis.

and $12,773 \mathrm{KWh} / \mathrm{yr}$, respectively. The energy utilization can be ascribed to the average yearly load demand in the health clinic. At the point when the electric power generated by PV modules surpasses the load demand of the health clinic, the excess electricity is stored in the batteries for use during low supply from the other electric sources. Løtveit et al. ${ }^{71}$ reported that the battery stored energy can be used not only to solve the daily load variation but can be used as an energy source after sundown. Notwithstanding that the PV/DG/B and PV/B hybrid energy systems have the highest energy production; the measure of carbon emission from the PV/GS/B hybrid energy system can be extensively high, contrasted with the renewable energy system (PV/B). Besides, considering the call for carbon emission reduction, the GS and associated GS-based hybrid energy system may not be a superior choice for the health clinic, making the PV/B the preferred choice for the Health clinic in Murzuq.

\section{Cost analysis result}

The capital, installation, maintenance, and operating costs of all components of the hybrid energy system are shown in Fig. 12. HOMER generates the cash flow to display the system cost summary.

The result shows that initial capital costs of the PV/GS/B, GS, and PV/B are $\$ 42,330, \$ 580$, and $\$ 30,500$, respectively, indicating the cost-effectiveness in utilizing PV/B hybrid energy system for renewable and electricity projects. ${ }^{72,73}$ The highest capital cost of PV/GS/B compared to PV/GS/B and GS can be ascribed to the conglomerate of components that make up the hybrid energy system. Considering the replacement cost, Fig. 12 displays the GS standalone energy system to have the lowest of $\$ 490$ in contrast with the other two hybrid energy systems (PV/ GS/B and PV/B). While the PV/GS/B and GS hybrid energy systems display high fuel consumption resulting in high emission, the PV/B shows no fuel consumption and as such negligible emission, making the PV/B hybrid energy system the most viable option for the health clinic.

\section{Emission and pollution analysis}

The greenhouse $(\mathrm{GH})$ emissions measurements drawn in the three hybrid energy systems using HOMER are presented in Table 7. It can be seen that the GS has the highest amount of carbon emission compared to the other two hybrid energy systems considered in this study.

Table 7. Emissions from the three hybrid energy systems.

Emissions $\left(\mathrm{Kg} \mathrm{year}^{-1}\right)$

System configuration

$$
\mathrm{CO}_{2}(\mathrm{Kg} / \mathrm{yr}) \quad \mathrm{CO}(\mathrm{Kg} / \mathrm{yr}) \quad \mathrm{SO}_{2}(\mathrm{Kg} / \mathrm{yr}) \quad \mathrm{NO}_{2}(\mathrm{Kg} / \mathrm{yr})
$$

\begin{tabular}{|l|c|c|c|l|}
\hline PV/GS/B & 28,308 & 106.2 & 166 & 81.2 \\
\hline PV/B & 0.0 & 0.0 & 0.0 & 0.0 \\
\hline GS & 39,216 & 284 & 170 & 83.1 \\
\hline
\end{tabular}


Employing the PV/B hybrid energy system for the health clinic project can significantly reduce carbon emission and is evident in Table 6 . The high measure of carbon emission observed in PV/GS/B and GS hybrid energy systems is related to the measure of liters of diesel devoured by the GS annually. ${ }^{51}$ Furthermore, the PV/B hybrid energy system provides more noteworthy reserve funds as far as $\mathrm{CO}_{2}, \mathrm{CO}$, and $\mathrm{SO}_{2}$ emission, contrasted with the other two hybrid energy systems. Comparatively, despite the two hybrid energy systems (PV/GS/B and GS) displaying evidence of high emission. The higher NPC and operating cost values observed in the PV/GS/B hybrid energy system compared with PV/B and GS disqualify the system as being a better choice to meet the electrical load demand of the health clinic in Murzuq. Furthermore, despite the low NPC and operating cost observed in the GS, the highest emission associated with the system deemed it not suitable to meet the renewable energy need of the clinic.

\section{Return on investment (ROI) analysis}

The financial feasibility of the investment for the health clinic in Murzuq requires further examination. Economic analysis indicator, for example, returns on investment (ROI) is regularly performed to comprehend the feasibility and sustainability of the project. The ROI examination is utilized to measure the gain or loss incurred from investing in a project. Return on investment is simply calculated by dividing the net profit by the invested cost throughout the investment. Figure 13 shows that the PV/B hybrid energy system has the highest ROI for the money invested which contrasted with PV/GS/B and GS hybrid energy systems.

The high value of ROI indicates the ability of the PV/B hybrid energy system to meet the electricity needs of the health clinic while providing a net benefit to the community. Furthermore, a large ROI for the PV/B showed the PV/B to provide a higher return on energy investment than the other two hybrid energy systems. The highest ROI for the PV/B system can also be

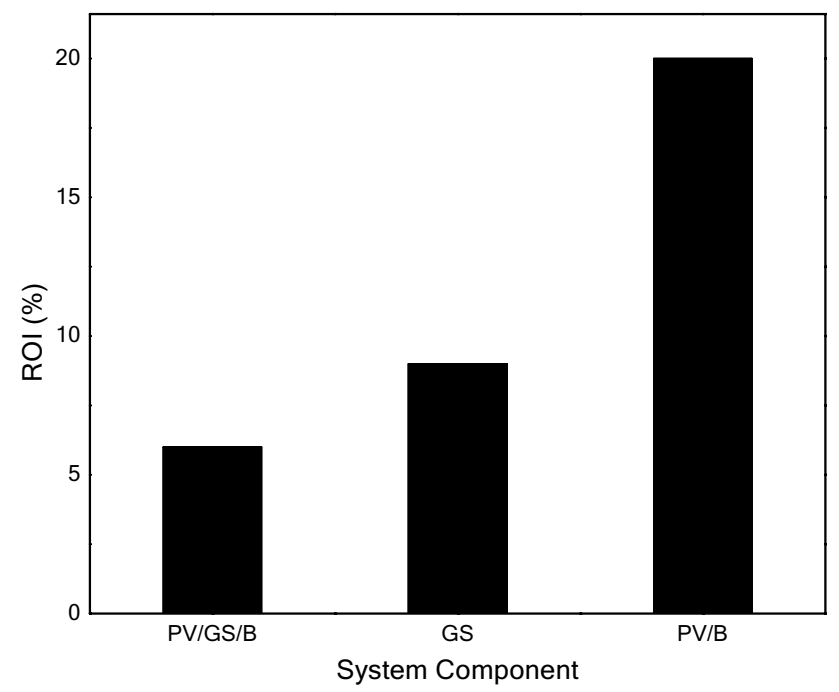

credited to the efficiency of the system and the capability of giving benefit all through the project life cycle.

\section{Conclusion}

The challenges of unsteady power supply to the remote communities necessitated by COVID-19 and the damage in the infrastructure and the electrical power network have created an urgent need for an alternative renewable energy source for electricity. The demand and cost of electricity have significantly increased as a result of enforced lockdowns and the COVID-19 pandemic. The pandemic has direct impacts on hospitals, health clinics, health personals, and energy consumption, resulting in an increased number of patients and extended working hours. In this study, three hybrid energy systems were used to provide energy to a health clinic in Murzuq and the investigation utilized measured data and HOMER software. It was evident from the evaluated and optimized results that the renewable energy-based PV/B has the lower NPC, COE, and operating cost compared to PV/GS/B hybrid energy system. Although the standalone generator set has the lowest NPC and operating cost, the system has the highest carbon emission compared to the other two hybrid energy systems, making it not suitable for the renewable energy project. The PV/B hybrid energy system is found to be the best option for an electricity source that meets the energy demand of the health clinic in Murzuq considering the environment and economy. The feasibility study demonstrated the sustainability of using renewable energy as the source of electricity for the clinic and the wider community considering the geographical location of the community. The findings also demonstrated that the renewable PV/B energy systems have the highest ROI value, making the renewable energy hybrid system the preferred choice to fulfill the health clinic electricity demand.

\begin{tabular}{|l|c|c|}
\multicolumn{1}{l}{ Abbreviation } & \multicolumn{1}{c}{ Definitions } & Units \\
\hline HOMER & $\begin{array}{c}\text { Hybrid optimization } \\
\text { model for electrical } \\
\text { renewables }\end{array}$ & - \\
\hline PV & Photovoltaic & - \\
\hline B & Battery & - \\
\hline NPC & Net present cost & $\$$ \\
\hline COE & Cost of energy & KWh \\
\hline GS & Generator set & - \\
\hline
\end{tabular}

Figure 13. Return on investment for the hybrid energy systems. 


\begin{tabular}{|c|c|c|}
\hline Abbreviation & Definitions & Units \\
\hline DC & Direct current & A (ampere) \\
\hline$A C$ & Alternating current & A (ampere) \\
\hline$c_{\text {ann }}$ & $\begin{array}{c}\text { Annualized total cost of } \\
\text { the whole system }\end{array}$ & \$/year \\
\hline CRF & Capital recovery factor & $\$$ \\
\hline N & Project life cycle & Years \\
\hline$i$ & Yearly interest rate & $\%$ \\
\hline$E_{\text {anloadserved }}$ & $\begin{array}{c}\text { Total yearly load served } \\
\text { by the system }\end{array}$ & KWh \\
\hline ROl & Return on investment & \\
\hline$c_{i, \text { ref }}$ & $\begin{array}{l}\text { The Reference system } \\
\text { Nominal annual cash } \\
\text { flow }\end{array}$ & $\$ / y r$ \\
\hline $\mathrm{Ci}$ & $\begin{array}{l}\text { The Current System } \\
\text { Nominal annual cash } \\
\text { flow }\end{array}$ & $\$ / y r$ \\
\hline$R_{\text {proj }}$ & Project lifetime & Years \\
\hline$C_{\text {сар }}$ & $\begin{array}{c}\text { Capital cost of the cur- } \\
\text { rent system }\end{array}$ & $\$$ \\
\hline$C_{\text {cap, ref }}$ & $\begin{array}{c}\text { Capital cost of the base } \\
\text { system }\end{array}$ & $\$$ \\
\hline $\mathrm{GH}$ & Greenhouse & - \\
\hline $\mathrm{CO}_{2}$ & Carbon dioxide & $\mathrm{Kg} / \mathrm{yr}$ \\
\hline $\mathrm{CO}$ & Carbon monoxide & $\mathrm{Kg} / \mathrm{yr}$ \\
\hline $\mathrm{SO}_{2}$ & Sulfur dioxide & $\mathrm{Kg} / \mathrm{yr}$ \\
\hline $\mathrm{NO}_{2}$ & Nitrogen dioxide & $\mathrm{Kg} / \mathrm{yr}$ \\
\hline
\end{tabular}

\section{REFERENCES}

1. I. Khan, A. Haleem, M. Javaid, Analysing COVID-19 pandemic through cases, deaths, and recoveries. J. Oral Biol. Craniofac Res 10(4), 450-469 (2020)

2. S. Susilawati, R. Falefi, A. Purwoko, Impact of COVID-19's Pandemic on the Economy of Indonesia. BIRCI J. 3(2), 1147-1156 (2020)

3. S.S. Qarnain, S. Muthuvel, S. Bathrinath, Review on government action plans to reduce energy consumption in buildings amid COVID-19 pandemic outbreak. Mater. Today 45, 1264-1268 (2021)

4. M. Carvalho, D. B. de Mello Delgado, K. M. de Lima, M. de Camargo Cancela, C. A. dos Siqueira, and D. L. B. de Souza, Effects of the COVID-19 pandemic on the Brazilian electricity consumption patterns. Int. J. Energy Res. 45(2), 3358-3364 (2021).

5. B. Debata, P. Patnaik, A. Mishra, COVID-19 pandemic! It's impact on people, economy, and environment. J. Public Affairs 20(4), e2372 (2020)

6. C.L. Karmaker, T. Ahmed, S. Ahmed, S.M. Ali, M.A. Moktadir, G. Kabir, Improving supply chain sustainability in the context of COVID-19 pandemic in an emerging economy: exploring drivers using an integrated model. Sustain. Prod. Consum. 26, 411-427 (2021)

7. Y.-C. Tsao, V.-V. Thanh, J.-C. Lu, H.-H. Wei, A risk-sharingbased resilient renewable energy supply network model under the COVID-19 pandemic. Sustain. Prod. Consum. 25, 484-498 (2021)

8. S.E. Hosseini, An outlook on the global development of renewable and sustainable energy at the time of Covid-19. Energy Res. Soc. Sci. 68, 101633 (2020)

9. S. Pradhan, D. Ghose, Shabbiruddin, Present and future impact of COVID-19 in the renewable energy sector: a case study on India. Energy Sources Part A 1-11 (2020).

10. N. J. Rowan, C. M. Galanakis, Unlocking challenges and opportunities presented by COVID-19 pandemic for cross-cutting disruption in agri-food and green deal innovations: Quo Vadis? Sci. Total Environ 141362 (2020).

11. H.M. Alhajeri, A. Almutairi, A. Alenezi, F. Alshammari, Energy demand in the state of Kuwait during the covid-19 pandemic: technical, economic, and environmental perspectives. Energies 13(17), 4370 (2020)

12. T. Ibn-Mohammed et al., A critical review of the impacts of COVID-19 on the global economy and ecosystems and opportunities for circular economy strategies. Resour. Conserv. Recycl. 105169 (I2020).

13. P. C. Okonkwo, I. U. Hassan, W. H. Beitelmal, Bamboo utilization as a sustainable building material: bamboo in buildings. In: Health and Well-Being Considerations in the Design of Indoor Environments. IGI Global, pp. 79-96 (2021).

14. E. Barhoumi et al., Renewable energy resources and workforce case study Saudi Arabia: review and recommendations. J. Therm. Anal. Calorim. 141(1), 221-230 (2020)

15. I.-M. García-Sánchez, A. García-Sánchez, Corporate social responsibility during COVID-19 pandemic. J. Open Innov. 6(4), 126 (2020)

16. H. Eroğlu, Effects of Covid-19 outbreak on environment and renewable energy sector. Environ. Dev. Sustain. 1-9 (2020)

17. M. Fu, H. Shen, COVID-19 and corporate performance in the energy industry. Energy Res. Lett. 1(1), 12967 (2020)

18. L. Olatomiwa, S. Mekhilef, O.S. Ohunakin, Hybrid renewable power supply for rural health clinics (RHC) in six geo-political zones of Nigeria. Sustain. Energy Technol. Assess. 13, 1-12 (2016) 
19. Y. Sawle, S. Gupta, A.K. Bohre, Review of hybrid renewable energy systems with comparative analysis of off-grid hybrid system. Renew. Sustain. Energy Rev. 81, 2217-2235 (2018)

20. E.M. Barhoumi, S. Farhani, P.C. Okonkwo, M. Zghaibeh, F. Bacha, Techno-economic sizing of renewable energy power system case study Dhofar Region-Oman. Int. J. Green Energy 18(8), 856-865 (2021)

21. P. C. Okonkwo et al., Economic evaluation of hybrid electrical systems for rural electrification: a case study of a rural community in Nigeria. Int. J. Green Energy 1-13 (2021).

22. P.C. Okonkwo et al., Economic analysis of cross-breed power arrangement for Salalah region in the Al-Khareef season. Int. J. Sustain. Energ. 40(2), 188-206 (2021)

23. C. Li et al., Techno-economic feasibility study of autonomous hybrid wind/PV/battery power system for a household in Urumqi, China. Energy 55, 263-272 (2013)

24. A. Kaabeche, Y. Bakelli, Renewable hybrid system size optimization considering various electrochemical energy storage technologies. Energy Convers. Manag. 193, 162-175 (2019)

25. S. Abdul-Wahab, Y. Charabi, A.M. Al-Mahruqi, I. Osman, S. Osman, Selection of the best solar photovoltaic (PV) for Oman. Sol. Energy 188, 1156-1168 (2019)

26. A.H. Mamaghani, S.A.A. Escandon, B. Najafi, A. Shirazi, F. Rinaldi, Techno-economic feasibility of photovoltaic, wind, diesel and hybrid electrification systems for off-grid rural electrification in Colombia. Renew. Energy 97, 293-305 (2016)

27. S. Farhani, P. C. Okonkwo, M. Zghaibeh, F. K. Al Housni, F. Bacha, Economic analysis and Comparison of stand alone and grid connected roof top photovoltaic systems. In: 2021 6th International Conference on Renewable Energy: Generation and Applications (ICREGA), pp. 223-228. IEEE

28. X. Xu, W. Hu, D. Cao, Q. Huang, C. Chen, Z. Chen, Optimized sizing of a standalone PV-wind-hydropower station with pumpedstorage installation hybrid energy system. Renew. Energy 147, 1418-1431 (2020)

29. C. Li, D. Zhou, H. Wang, Y. Lu, D. Li, Techno-economic performance study of stand-alone wind/diesel/battery hybrid system with different battery technologies in the cold region of China. Energy 192, 116702 (2020)

30. H. Mehrjerdi, Modeling, integration, and optimal selection of the turbine technology in the hybrid wind-photovoltaic renewable energy system design. Energy Convers. Manag. 205, 112350 (2020)

31. A. Razmjoo, R. Shirmohammadi, A. Davarpanah, F. Pourfayaz, A. Aslani, Stand-alone hybrid energy systems for remote area power generation. Energy Rep. 5, 231-241 (2019)

32. L. Olatomiwa, R. E. Blanchard, Maximizing the penetration levels of hybrid renewable energy systems in rural areas with demand side management approaches in achieving SDGs (2019).

33. A.S. Aziz, M.F.N. Tajuddin, M.R. Adzman, A. Azmi, M.A. Ramli, Optimization and sensitivity analysis of standalone hybrid energy systems for rural electrification: a case study of Iraq. Renew. Energy 138, 775-792 (2019)

34. I.P. Panapakidis, D.N. Sarafianos, M.C. Alexiadis, Comparative analysis of different grid-independent hybrid power generation systems for a residential load. Renew. Sustain. Energy Rev. 16(1), 551-563 (2012)

35. S.K. Nandi, H.R. Ghosh, A wind-PV-battery hybrid power system at Sitakunda in Bangladesh. Energy Policy 37(9), 3659-3664 (2009)

36. L. Lozano, E. M. Querikiol, M. L. S. Abundo, L. M. Bellotindos, Techno-economic analysis of a cost-effective power generation system for off-grid island communities: a case study of Gilutongan Island, Cordova, Cebu, Philippines. Renew. Energy (2019).

37. S. Sinha, S. Chandel, Review of software tools for hybrid renewable energy systems. Renew. Sustain. Energy Rev. 32, 192-205 (2014)
38. O. Mestre et al., HOMER: a homogenization software-methods and applications (2013).

39. B. U. Kansara, B. Parekh, Modelling and simulation of distributed generation system using HOMER software. In: 2011 International Conference on Recent Advancements in Electrical, Electronics and Control Engineering, pp. 328-332. IEEE (2011)

40. A. H. Al-Badi, H. Bourdoucen, Economic analysis of hybrid power system for rural electrification in Oman. In: 2009 2nd International Conference on Adaptive Science \& Technology (ICAST), pp. 284-289. IEEE (2009)

41. S. Bahramara, M.P. Moghaddam, M. Haghifam, Optimal planning of hybrid renewable energy systems using HOMER: a review. Renew. Sustain. Energy Rev. 62, 609-620 (2016)

42. W.M. Amutha, V. Rajini, Cost benefit and technical analysis of rural electrification alternatives in southern India using HOMER. Renew. Sustain. Energy Rev. 62, 236-246 (2016)

43. C.A. Onwe, D. Rodley, S. Reynolds, Modelling and simulation tool for off-grid PV-hydrogen energy system. Int. J. Sustain. Energy 39(1), 1-20 (2020)

44. S. Ebrahimi, M. Jahangiri, H.A. Raiesi, A.R. Ariae, Optimal planning of on-grid hybrid microgrid for remote Island Using HOMER software, Kish in Iran. Int. J. Energy 3(2), 13-21 (2019)

45. G. Map. https://maps.google.com/. [38] Map graphics revolution. http://www.maphill.com/.

46. M. g. Revolution. http://www.maphill.com/

47. O.A. Mohamed, S.H. Masood, A brief overview of solar and wind energy in Libya: current trends and the future development. IOP Conf. Ser 377(1), 012136 (2018)

48. Y. Kassem, H. Camur, O.A. Abughinda, Solar energy potential and feasibility study of a 10MW grid-connected solar plant in Libya. Eng. Technol. Appl. Sci. Res. 10(4), 5358-5366 (2020)

49. H. Energy, Homer pro version 3.7 user manual, HOMER Energy: Boulder, CO, USA (2016).

50. S. Choice, kW solar systems: pricing, output, and returns. Solar Choice Solar PV Energy System Installation Brokers 5kW Solar Systems Pricing Output and Returns Comments.

51. M. Mamun, M. Islam, M. Hasanuzzaman, J. Selvaraj, Effect of tilt angle on the performance and electrical parameters of a PV module: comparative indoor and outdoor experimental investigation. Energy Built Environ (2021)

52. R. Conceição, H.G. Silva, L. Fialho, F.M. Lopes, M. CollaresPereira, PV system design with the effect of soiling on the optimum tilt angle. Renew. Energy 133, 787-796 (2019)

53. K. Divya, J. Østergaard, Battery energy storage technology for power systems - an overview. Electric Power Syst. Res. 79(4), 511-520 (2009)

54. A.A. Adesanya, J.M. Pearce, Economic viability of captive offgrid solar photovoltaic and diesel hybrid energy systems for the Nigerian private sector. Renew. Sustain. Energy Rev. 114, 109348 (2019)

55. W. T. Alsaiaf, Dynamic macro-economic analysis of an oil price shock, fiscal, monetary and exchange rate policies for Libya in the MENA Region (2019).

56. S. Mirhassani, H.C. Ong, W. Chong, K. Leong, Advances and challenges in grid tied photovoltaic systems. Renew. Sustain. Energy Rev. 49, 121-131 (2015)

57. W.H. Beitelmal, P.C. Okonkwo, F. Al Housni, W. Alruqi, O. Alruwaythi, Accessibility and sustainability of hybrid energy systems for a cement factory in Oman. Sustainability 13(1), 93 (2021)

58. A. Shiroudi, R. Rashidi, G. Gharehpetian, S. Mousavifar, A.A. Foroud, Case study: simulation and optimization of photovoltaicwind-battery hybrid energy system in Taleghan-Iran using homer software. J. Renew. Sustain. Energy 4(5), 053111 (2012)

59. M. Krarti, M. Aldubyan, Review analysis of COVID-19 impact on electricity demand for residential buildings. Renew. Sustain. Energy Rev. 110888 (2021). 
60. T. Givler, P. Lilienthal, Using HOMER software, NREL's micropower optimization model, to explore the role of gen-sets in small solar power systems; case study: Sri Lanka. National Renewable Energy Lab., Golden, CO (US) (2005).

61. R. Sen, S.C. Bhattacharyya, Off-grid electricity generation with renewable energy technologies in India: an application of HOMER. Renew. Energy 62, 388-398 (2014)

62. F.A.B. Budes, G.V. Ochoa, L.G. Obregon, A. Arango-Manrique, J.R.N. Álvarez, Energy, economic, and environmental evaluation of a proposed solar-wind power on-grid system using HOMER Pro®: a case study in Colombia. Energies 13(7), 1662 (2020)

63. K. Murugaperumal, P.A.D.V. Raj, Feasibility design and technoeconomic analysis of hybrid renewable energy system for rural electrification. Sol. Energy 188, 1068-1083 (2019)

64. K. Anwar, S. Deshmukh, S.M. Rizvi, Feasibility and sensitivity analysis of a hybrid photovoltaic/wind/biogas/fuel-cell/diesel/battery system for off-grid rural electrification using homer. J. Energy Res. Technol. 142(6), 061307 (2020)

65. C.H.B. Apribowo, M.H. Ibrahim, M.R.B. Purnomo, Design and economic analysis of floating PV-wind turbine plant for renewable energy supply in Indonesia. AIP Conf. Proc. 2217(1), 030191 (2020)

66. S. Mandal, B.K. Das, N. Hoque, Optimum sizing of a stand-alone hybrid energy system for rural electrification in Bangladesh. J. Clean. Prod. 200, 12-27 (2018)
67. S.A. Sadat, J. Faraji, M. Babaei, A. Ketabi, Techno-economic comparative study of hybrid microgrids in eight climate zones of Iran. Energy Sci. Eng. 8(9), 3004-3026 (2020)

68. M.N. Ashtiani, A. Toopshekan, H. Yousefi, A. Maleki, Technoeconomic analysis of a grid-connected PV/battery system using the teaching-learning-based optimization algorithm. Sol. Energy 203, 69-82 (2020)

69. B.K. Das, M.S.H. Tushar, R. Hassan, Techno-economic optimisation of stand-alone hybrid renewable energy systems for concurrently meeting electric and heating demand. Sustain. Cities Soc. 68, 102763 (2021)

70. S.P. Ayeng'o, H. Axelsen, D. Haberschusz, D.U. Sauer, A model for direct-coupled PV systems with batteries depending on solar radiation, temperature and number of serial connected PV cells. Sol. Energy 183, 120-131 (2019)

71. M. Løtveit, J. A. Suul, E. Tedeschi, M. Molinas, A study of biomass in a hybrid stand-alone Micro-Grid for the rural village of Wawashang, Nicaragua. In 2014 Ninth International Conference on Ecological Vehicles and Renewable Energies (EVER), pp. 1-7. IEEE (2014)

72. F. Ali, M. Ahmar, Y. Jiang, M. AlAhmad, A techno-economic assessment of hybrid energy systems in rural Pakistan. Energy 215, $119103(2021)$

73. E.B. Agyekum, C. Nutakor, Feasibility study and economic analysis of stand-alone hybrid energy system for southern Ghana. Sustai. Energy Technol. Assessments 39, 100695 (2020) 